\title{
Enraizamento de estacas de erva-mate (Ilex paraguariensis A. St.-Hill.) provenientes de brotações rejuvenescidas
}

\author{
BITENCOURT, J. ; ZUFFELLATO-RIBAS, K.C.. ; WENDLING, I. ; KOEHLER, H.S. ${ }^{3}$ \\ ${ }^{2}$ Departamento de Botânica, Setor de Ciências Biológicas, Universidade Federal do Paraná (UFPR), Centro \\ Politécnico- Jardim das Américas, CP: 19031, CEP: 81531-970, Curitiba - PR *kazu@ufpr.br ${ }^{3}$ Embrapa Florestas, \\ Colombo - PR. ${ }^{4}$ Departamento de Fitotecnia e Fitossanitarismo, Setor de Ciências Agrárias, Universidade Federal \\ do Paraná (UFPR).
}

\begin{abstract}
RESUMO: A erva-mate (Ilex paraguariensis A. St.-Hill.) é espécie nativa da América do Sul, de grande importância econômica devido a seu consumo na forma de chás e também vem sendo amplamente estudada nas áreas de farmacologia e biotecnologia. No entanto, tem baixo capacidade de propagação, seja ela sexuada ou assexuada. Um dos principais efeitos da maturação é a perda da capacidade de enraizamento, desta forma, o presente trabalho teve como objetivos observar a influência do rejuvenescimento e aplicação de ácido indol butírico (IBA) no enraizamento de estacas caulinares de erva-mate. Foram confeccionadas estacas a partir de brotações do ano de árvores de 13 anos, assim como de brotos rejuvenescidos, obtidos da decepa de árvores com 17 anos. As estacas foram tratadas com IBA em solução nas seguintes concentrações: $0,1500,3000,4500$ e $6000 \mathrm{mg} \mathrm{L}^{-1}$, resultando em 5 tratamentos para cada tipo de estaca. O plantio foi realizado em caixas plásticas preenchidas com vermiculita e casca-de-arroz carbonizada na proporção de 1:1 e após 90 dias em casa-de-vegetação, foram avaliadas as seguintes variáveis: porcentagem de estacas enraizadas, número de raízes/estaca, comprimento das 3 maiores raízes/estaca, porcentagem de estacas vivas, com calos e mortas. A análise estatística mostrou que o material rejuvenescido apresentou os melhores resultados quanto à porcentagem de estacas enraizadas, assim como de número e comprimento de raízes. Já a aplicação da auxina sintética não influenciou no enraizamento das estacas de nenhum dos dois tipos, de modo que os tratamentos com IBA não diferiram entre si estatisticamente.
\end{abstract}

Palavras-chave: estaquia, ácido indol butírico, rejuvenescimento

\begin{abstract}
Rooting of "erva-mate" (Ilex paraguariensis A. St.-Hill.) cuttings from rejuvenated sprouts. "Erva-mate" (Ilex paraguariensis A. St.-Hill.) is native to South America and has great economic importance due to its consumption as tea; it has also been studied in pharmacology and biotechnology. However, this species has low propagation ability, either sexually or not. One of the main effects of maturation is the loss of rooting ability; thus, this paper aimed to verify the influence of rejuvenation and application of indolebutyric acid (IBA) on the rooting of stem cuttings from "erva-mate". Cuttings were obtained using sprouts of the year from 13-year-old trees and rejuvenated sprouts from stump regrowth of 17-year-old trees. Cuttings were treated with IBA solution at the following concentrations: 0, 1500, 300, 4500 and $6000 \mathrm{mg} \mathrm{L}^{-1}$, resulting in 5 treatments for each cutting type. Planting was done in plastic containers filled with vermiculite and carbonized rice bark at 1:1 proportion. After 90 days in greenhouse, cuttings were evaluated for the following variables: percentage of cuttings with roots, number of roots/cutting, length of the three largest roots/cutting, and percentage of live cuttings, those with callus and dead ones. Statistical analysis indicated that the rejuvenated material had the best results concerning percentage of cuttings with root, and number and length of roots. The application of synthetic auxin did not influence the rooting of cuttings from neither type, so that IBA treatments did not differ statistically.
\end{abstract}

Key words: cutting, indolebutyric acid, rejuvenation

Recebido para publicação em 11/05/2008

Aceito para publicação em 06/02/2009

Rev. Bras. PI. Med., Botucatu, v.11, n.3, p.277-281, 2009. 


\section{INTRODUÇÃO}

Ilex paraguariensisA. St.-Hill. (Aqüifoliaceae), também conhecida como erva-mate, é espécie arbórea nativa da floresta ombrófila mista na América do Sul, cujas folhas são largamente utilizadas na medicina e consumidas na forma de chá. É espécie de grande importância sócio-econômica para a região sul do Brasil, Paraguaie Argentina (Fowler \& Sturion, 2000; Lorenzi \& Matos, 2002).

A taxa de germinação das sementes é baixa e desuniforme, devido à imaturidade do embrião, o que dificulta a produção de mudas, tornando a estaquia uma alternativa à propagação desta espécie (Carvalho, 1994; Fowler \& Sturion, 2000).

A passagem da fase juvenil para a adulta pode alterar a capacidade de enraizamento das plantas (Wendling \& Xavier, 2001), de modo que a perda da capacidade de formar raízes é um dos principais efeitos da maturação (Diaz-Sala et al., 1996). Isto gera problemas na propagação vegetativa porque, muitas vezes, as características desejadas de uma planta matriz são expressas depois da maturidade (Hartmann et al., 2002)

Matrizes selecionadas e multiplicadas assexuadamente passam a constituir clones, processo que pode ser usado no resgate do material superior e em muitos casos, o resgate de matrizes requer a obtenção de material juvenil com capacidade de enraizar. $\mathrm{O}$ resgate pode ser feito por meio de corte raso e a rebrota destas árvores que alcançaram a maturidade pode ser utilizada na propagação vegetativa (Alfenas et al., 2004; Borges Júnior et al., 2004). Segundo Hartmann et al. (2002), os brotos provenientes das gemas laterais de base possuem maior juvenilidade dos tecidos e são mais vigorosos, fatores que melhoram a capacidade de enraizamento dos mesmos. Além disso, plantas podadas podem fornecer grandes quantidades de material juvenil para a produção de mudas.

De acordo com Medrado et al. (2002), mudas de boa qualidade representam o melhor insumo para o estabelecimento de um bom plantio de erva-mate. Porém, uma das limitações da propagação vegetativa desta espécie por estaquia é a falta de métodos eficientes de obtenção de propágulos rejuvenescidos, com alta capacidade de enraizamento (Wendling et al., 2007).

Sendo assim, os objetivos deste trabalho foram verificar a influência do rejuvenescimento por meio de decepa e aplicação da auxina sintética, ácido indol butírico (IBA), no enraizamento de estacas caulinares de erva-mate.

\section{MATERIAL E MÉTODO}

O experimento foi conduzido em casa de vegetação pertencente à Embrapa Florestas, localizada em Colombo - PR, entre janeiro (verão) e abril (outono) de 2007. Foram confeccionados dois tipos de estacas, de acordo com a origem do material utilizado, sendo os seguintes: a) estacas de brotações do ano, provenientes de árvores com 13 anos de idade e b) estacas de rebrota, provenientes de rebrota de decepa realizada em árvores de 17 anos de idade inverno de 2006, a $60 \mathrm{~cm}$ do solo - de modo que a rebrota possuía cerca de 6 meses de idade.

As estacas foram confeccionadas com cerca de $12 \mathrm{~cm}$ de comprimento e duas folhas com a área reduzida à metade, cortadas em bisel na base e retas no ápice. Adesinfestação foi realizada com hipoclorito de sódio a $0,5 \%$ por 5 minutos, seguida de lavagem em água corrente por 5 minutos. As bases das estacas foram então imersas em uma solução com fungicida sistêmico (Benomyl, $1 \mathrm{~g} \mathrm{~L}^{-1}$ ) por 15 minutos e, posteriormente, tratadas com IBA em solução $(50 \%$ alcoólica) por 10 segundos, nas concentrações de 0; 1500; 3000; 4500 e $6000 \mathrm{mg} \mathrm{L}^{-1}$. O plantio foi realizado em caixas plásticas, utilizando casca-de-arroz carbonizada e vermiculita de granulometria média como substrato, na proporção de 1:1. Após 90 dias em casa-de-vegetação climatizada (U.R. $=85 \%$ e Temperatura $=20-24^{\circ} \mathrm{C}$ ), foram avaliadas as seguintes variáveis: porcentagem de estacas enraizadas, número de raízes por estaca, comprimento das 3 maiores raízes por estaca, porcentagem de estacas com calos, vivas e mortas.

Os dados foram analisados segundo delineamento inteiramente casualizado, com arranjo fatorial de 5 tratamentos e 2 tipos de estacas $(5 \times 2)$, com 4 repetições de 20 estacas por unidade experimental. Os dados obtidos foram submetidos à análise de variância. Inicialmente, as variâncias dos tratamentos foram avaliadas quanto a homogeneidade pelo teste de Bartlett. As variáveis cujas variâncias mostraram-se homogêneas tiveram as médias dos tratamentos testadas por meio do teste de F. Quando os resultados revelaram existir diferenças significativas entre as médias dos tratamentos, foram comparadas pelo teste de Tukey ao nível de $5 \%$ de probabilidade.

\section{RESULTADO E DISCUSSÃO}

Aanálise de variância (Tabela 1) revelou, para as variáveis analisadas, que a interação entre as concentrações de IBA e os tipos de estacas não foram significativas, indicando que estes fatores são independentes. Somente o fator tipo de estaca mostrou diferença estatisticamente significativa.

O teste de comparação de médias (Figura 1) foi feito utilizando apenas as médias dos resultados dos dois tipos de estacas, uma vez que os tratamentos com IBA não diferiram entre si estatisticamente.

As estacas provenientes de rebrota, compostas de material rejuvenescido, obtiveram maior 
TABELA1. Resultados da análise de variância para as variáveis porcentagem de estacas enraizadas, número de raízes por estaca, comprimento médio das três maiores raízes por estaca (Comp. $3>$ raízes), porcentagem de estacas com calos, vivas e mortas.

\begin{tabular}{|c|c|c|c|c|c|c|c|}
\hline \multirow[b]{2}{*}{ Fator de variação } & \multirow[b]{2}{*}{ G.L. } & \multicolumn{6}{|c|}{ Quadrado Médio } \\
\hline & & $\begin{array}{c}\text { Estacas } \\
\text { enraizadas (\%) }\end{array}$ & $\begin{array}{l}\text { № raízes } \\
\text { por estaca }\end{array}$ & $\begin{array}{l}\text { Comp. } 3 \text { > } \\
\text { raízes }(\mathrm{mm})\end{array}$ & $\begin{array}{c}\text { Estacas com } \\
\text { calos }(\%)\end{array}$ & $\begin{array}{l}\text { Estacas } \\
\text { vivas (\%) }\end{array}$ & $\begin{array}{c}\text { Estacas } \\
\text { mortas (\%) }\end{array}$ \\
\hline IBA & 4 & $158,44^{\mathrm{ns}}$ & $5,88^{\mathrm{ns}}$ & 74,32 ns & 44,69 ns & $68,13^{\text {ns }}$ & 65,00 ns \\
\hline Tipo de estaca & 1 & $32490,00^{* *}$ & $1192,14^{\star *}$ & $5443,12^{\star *}$ & $1822,50^{\star *}$ & $2030,63^{\star *}$ & $8555,63^{\star \star}$ \\
\hline IBA x Tipo & 4 & $47,81^{\mathrm{ns}}$ & 15,20 ns & 43,33 ns & 61,56 ns & 177,50 ns & 133,75 ns \\
\hline Erro & 30 & 185,83 & 13,16 & 57,92 & 47,08 & 130,21 & 100,63 \\
\hline Coeficiente de variação (\%) & & 36,84 & 46,84 & 47,23 & 62,38 & 44,97 & 37,68 \\
\hline Qui -quadrado & & 15,26 & 16,47 & 15,58 & 8,91 & 7,65 & 12,03 \\
\hline
\end{tabular}

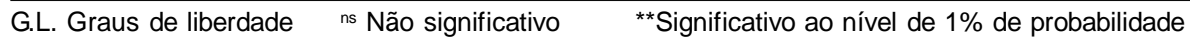

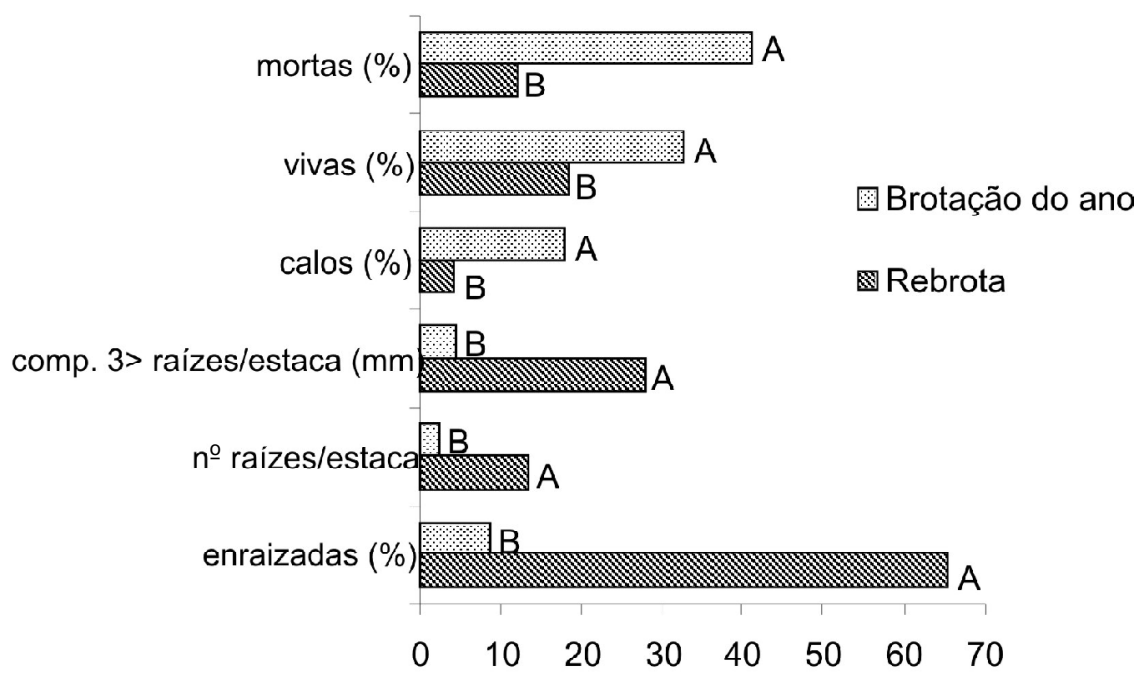

FIGURA 1. Resultados do teste de comparação de médias para as variáveis porcentagem de estacas enraizadas, número de raízes por estaca, comprimento médio das três maiores raízes por estaca, porcentagem de estacas com calos, vivas e mortas. Médias seguidas da mesma letra não diferem estatisticamente entre si pelo teste de Tukey ao nível de $5 \%$ de probabilidade.

porcentagem de enraizamento $(65,50 \%)$, assim como maior número de raízes (13,20 raízes/estaca) e maior comprimento médio das três maiores raízes $(27,78 \mathrm{~mm} /$ estaca) quando comparadas àquelas provenientes de brotações do ano $(8,50 \%$ de enraizamento;2,27 raízes e 4,45mm; respectivamente). Isto indica que o rejuvenescimento dos ramos para coleta de material é eficiente na otimização do enraizamento de estacas de erva-mate.

Hartmann et al. (2002) afirmam que o rejuvenescimento pode ser obtido, entre outros métodos, por meio de decepa da planta matriz. Os ramos obtidos terão maior capacidade de enraizamento, o que muitas vezes torna possível a propagação vegetativa de plantas difíceis de enraizar na estaquia convencional. Os resultados obtidos no presente trabalho corroboram com esta afirmação, uma vez que as estacas provenientes de rebrota apresentaram resultados superiores de enraizamento quando comparadas às de brotação do ano.

Resultado semelhante foi obtido por Monteuuis et al. (1995), em experimento com Acacia mangium, no qual as estacas provenientes de decepa obtiveram maior enraizamento do que aquelas de brotações apicais de plantas da mesma idade daquelas decepadas. Wendling \& Xavier (2003) concluíram que a miniestaquia seriada é indicada no rejuvenescimento de clones de Eucalyptus grandis com baixo potencial de enraizamento, enquanto Schuch et al. (2007) obtiveram altas taxas enraizamento (chegando a 66,8\%) de mirtilo (gênero Vaccinium) in vitro, sucesso este atribuído ao rejuvenescimento obtido pela micropropagação.

Medrado et al. (2002) sugerem que a 
recuperação de ervais degradados pode ser realizada por meio de decepa total das árvores, cuja produtividade está baixa e isto estimulará a formação de novas brotações, que serão vigorosas. Os resultados obtidos no presente trabalho mostram que estes brotos podem também ser coletados para a produção de mudas desta espécie por meio da estaquia.

A aplicação de IBA não afetou o enraizamento, o que pode indicar uma quantidade endógena de auxinas suficiente para a promoção do processo de formação de raízes nas estacas rejuvenescidas, uma vez que as estacas maduras não enraizaram.

Em experimento com estacas provenientes de decepa de Eucalyptus cloeziana, uma espécie considerada de difícil enraizamento, Almeida et al. (2007) obtiveram enraizamento superior a $90 \%$ das estacas coletadas de brotações de clones com 5 anos de idade e a aplicação de IBA não influenciou na formação de raízes destas estacas, assim como no presente trabalho. Os mesmos autores observaram ainda que em clones com 15 anos de idade, a aplicação de IBA foi significativa para alguns dos clones testados, mas de maneira geral, os clones com 5 anos de idade foram os que mostraram maior predisposição ao enraizamento.

As estacas provenientes de brotação do ano apresentaram maior porcentagem de estacas com calos $(17,75 \%)$, vivas $(32,50 \%)$ e mortas $(41,25 \%)$, quando comparadas àquelas provenientes de rebrota (4,25\%; $18,25 \%$ e $12,00 \%$ respectivamente), uma vez que foram as de menor enraizamento.

Iritani (1981), em experimento com estacas coletadas de plantas matrizes de erva-mate com 40 anos de idade, observou alta mortalidade das estacas, chegando a 90\%. Porém, Inoue \& Putton (2007), em experimento com diversas espécies arbóreas, obtiveram $68,7 \%$ de enraizamento das estacas de erva-mate tratadas com o produto comercial Enraizador Bioflora ${ }^{\circledR}$.

No presente trabalho, a aplicação de IBA não otimizou o enraizamento das estacas de brotação do ano, o que pode indicar a ausência de um co-fator necessário ao enraizamento ou até mesmo a presença de composto que diminua o potencial de enraizamento de estacas provenientes de material adulto. Segundo Hartmann et al. (2002), o material que não apresenta enraizamento com a aplicação de regulador vegetal é classificado como difícil de enraizar, porque o fator limitante à formação de raízes não é ausência de um hormônio, mas pode ser a presença de um inibidor de enraizamento ou deficiência de algum composto ou nutriente necessário ao processo.

Em experimento com Acacia mangium, Poupard et al. (1994) observaram que estacas provenientes de mudas produzidas a partir de sementes enraizaram melhor do que aquelas provenientes de rebrota, o que mostra os efeitos negativos da maturação no enraizamento. Isto pode ocorrer devido a uma deficiência de promotores e excesso de inibidores de enraizamento no material provenientes de plantas adultas. Esta presença de inibidores do enraizamento pode justificar a baixa porcentagem de estacas enraizadas provenientes de material adulto, mesmo com a aplicação de IBA.

Nas condições do presente trabalho, é possível concluir que ramos rejuvenescidos de ervamate possuem maior potencial para o enraizamento e a aplicação de IBA não influenciou a formação de raízes nas estacas desta espécie.

\section{REFERÊNCIA}

ALFENAS, A.C. et al. Clonagem e doenças do Eucalipto. Viçosa: Editora UFV, 2004. 442p.

ALMEIDA, F.D. et al. Propagação vegetativa de árvores selecionadas de Eucalyptus cloeziana F. Muell. por estaquia. Revista Árvore, v.31, n.3, p.445-53, 2007. BORGES JÚNIOR, N. et al. Rebrota de cepas de árvores adultas de acácia-negra (Acacia mearnsii De Wild.). Revista Árvore, v.28, n.4, p.611-5, 2004.

CARVALHO, P.E.R. Espécies florestais brasileiras: recomendações silviculturais, potencialidades e uso da madeira. Colombo: Embrapa Florestas, 1994. 640p. DIAZ-SALA, C. et al. Maturation-related loss in rooting competence by loblolly pine stem cuttings: the role of auxin transport, metabolism and tissue sensitivity. Physiologia Plantarum, v.97, n.3, p.481-90, 1996. FOWLER, J.A.P.; STURION, J.A. Aspectos da formação do fruto e da semente na germinação de erva-mate. Colombo: Embrapa Florestas, 2000. 5p. (Embrapa Florestas. Comunicado Técnico, 45).

HARTMANN, H.T. et al. Plant propagation: principles and pratices. 7.ed. New Jersey: Prentice Hall, 2002. 880p. INOUE, M.T.; PUTTON, V. Macropropagação de 12 espécies arbóreas da floresta ombrófila mista. Floresta, v.37, n.1, p.55-61, 2007.

IRITANI, C. Ação de reguladores do crescimento na propagação vegetativa por estaquia de Ilex paraguariensis Saint Hilaire e Araucaria angustifolia (Bert) O. Ktze. 1981. 163p. Dissertação (Mestrado em Ciências - Engenharia Florestal) - Universidade Federal do Paraná, Curitiba.

LORENZI, H.; MATOS, F.J.A. Plantas medicinais do Brasil: nativas e exóticas. Nova Odessa: Instituto Plantarum, 2002. p.71-2.

MEDRADO, M.J.S. et al. Recuperação de ervais degradados. Colombo: Embrapa Florestas, 2002. 6p. (Embrapa Florestas. Comunicado Técnico, 86). MONTEUUIS, O. et al. Rooting Acacia mangium cuttings of different physiological age with reference to leaf morphology as a phase change maker. Silvae Genetica, v.44, n.2-3, p.150-4, 1995.

POUPARD, C. et al. Rooting Acacia mangium cuttings: effects of age, within-shoot position and auxin treatment. Silvae Genetica, v.43, n.4, p.226-30, 1994.

$\mathrm{SCHUCH}, \mathrm{M} . W$. et al. AIB e substrato na produção de mudas de mirtilo cv. "Climax" através de microestaquia. Ciência Rural, v.37, n.5, p.1446-9, 2007. 
WENDLING, I. et al. Produção e sobrevivência de miniestacas e minicepas de erva-mate cultivadas em sistema semi-hidropônico. Pesquisa Agropecuária Brasileira, v.42, n.2, p.289-92, 2007.

WENDLING, I.; XAVIER, A. Gradiente de maturação e rejuvenescimento aplicado e espécies floretais. Floresta e Ambiente, v.8, n.1, p.187-94, 2001.

WENDLING, I.; XAVIER, A. Miniestaquia seriada no rejuvenescimento de clones Eucalyptus. Pesquisa Agropecuária Brasileira, v.38, n.4, p.475-80, 2003. 